\title{
Intensity of Local Skin Reactions During 5-Fluorouracil Treatment Related to the Number of Actinic Keratosis Lesions: A Post Hoc, Exploratory Analysis
}

Eggert Stockfleth $\cdot$ Nathalie Bégeault $\cdot$ Alain Delarue

Received: November 11, 2021 / Accepted: December 10, 2021 / Published online: December 26, 2021

(C) The Author(s) 2021

\begin{abstract}
Introduction: Actinic keratoses (AK) are epithelial lesions caused by chronic skin exposure to ultraviolet light that can progress into squamous cell carcinoma. Although several treatments are effective, they are associated with severe skin reactions, which might be related to the extent of the disease. This study aimed to examine the relationship between the severity of local skin reactions during treatment with 5-fluorouracil $4 \%$ cream and the number of AK lesions at baseline.

Methods: This post hoc analysis pooled data from two multicentre randomised phase III studies (HD-FUP3B-048, HD-FUP3B-049) in patients with AK treated with topical 5-fluorouracil $4 \%$ once daily (OD) or $5 \%$ twice daily (BID) for 4 weeks. First, we compared the severity, assessed using a numerical rating scale, of the local skin reactions between
\end{abstract}

Supplementary Information The online version contains supplementary material available at https:// doi.org/10.1007/s13555-021-00668-9.

E. Stockfleth $(\bowtie)$

Department of Dermatology, Ruhr-University

Bochum, Gudrunstraße 56, 44791 Bochum,

Germany

e-mail: eggert.stockfleth@klinikum-bochum.de

N. Bégeault · A. Delarue

Pierre Fabre Dermatologie, Les Cauquillous, 81500

Lavaur, France 5-fluorouracil $4 \%$ and 5\%. Then, we investigated the relationship between the number of lesions at baseline and severe skin reactions with 5-fluorouracil 4\% OD.

Results: Safety data were included from 397 patients who had received 5-fluorouracil 4\% (348 in study HD-FUP3B-048, 49 in study HDFUP3B-049) OD and 342 (HD-FUP3B-048) who had received 5-fluorouracil 5\% BID. For most skin reactions, severe ones were more common in patients treated with 5-fluorouracil 5\% cream BID than in those treated with 5-fluorouracil 4\% cream OD $(P<0.05)$. With 5 -fluorouracil $4 \%$ $\mathrm{OD}$, the incidence of severe erythema was significantly higher in patients with at least 10 lesions (46\%) than in patients with 5-10 lesions (28\%; $P<0.001)$. Similar results were observed for the other local skin reactions.

Conclusion: Treatment with 5-fluorouracil 4\% cream OD was associated with less severe local skin reactions than 5-fluorouracil 5\% BID. The number of AK lesions at baseline seems to have predictive value regarding the severity of local skin reactions that appear during treatment.

\section{PLAIN LANGUAGE SUMMARY}

In order to prevent recurrence of actinic keratosis lesions and their progression to invasive squamous cell carcinoma, topical treatment of actinic keratosis often involves treating the field 
of cancerisation to clear visible and subclinical lesions. The occurrence of local adverse skin reactions during treatment can affect patient adherence to therapy and therefore compromise efficacy. A thorough understanding of the relationships between changes in lesions, actinic keratosis remission and tolerability of topical treatments over time is necessary to manage patient expectations, ensure treatment adherence and optimise clinical outcomes. This exploratory study used pooled data from two pivotal phase III studies to compare local skin reaction severity between 5-fluorouracil 4\% cream applied once daily and 5-fluorouracil 5\% cream applied twice daily, then to examine the relationship between the severity of local skin reactions during treatment and the number of actinic keratosis lesions at baseline. Local skin reactions appeared to be more severe in patients with more than 10 actinic keratosis lesions at baseline than in those with 5 to 10 lesions. Using a cut-off value of 10 lesions pre-treatment, healthcare practitioners can forewarn patients accordingly of potentially more severe local adverse skin reactions in order to motivate them to complete their treatment, thus ensuring treatment efficacy. If patients are likely to experience intolerable severe skin reactions, practitioners can plan to introduce an appropriate rescue treatment.

Keywords: Actinic keratosis; 5-Fluorouracil; Local skin reactions; Topical

\section{Key Summary Points}

Why carry out this study?

The occurrence of severe local adverse skin reactions during topical treatment can affect patient adherence to therapy and therefore compromise efficacy.

By their mode of action, topical treatments for actinic keratosis (AK) may cause local skin reactions. The severity of local skin reactions may be due to the extent of the field of cancerisation.

\section{What was learned from the study?}

Treatment of AK with topical

5-fluorouracil 4\% once daily showed less severe local skin reactions compared with a $5 \%$ formulation twice daily.

A cut-off value of 10 pre-treatment lesions seems to be meaningful for anticipating possibly severe skin reactions during topical 5-fluorouracil treatment.

\section{INTRODUCTION}

Actinic keratoses (AK) are epithelial lesions composed of proliferating neoplastic keratinocytes that manifest as macules, papules, or superficial scaly plaques [1-3]. They occur on sun-exposed areas including the face, scalp, ears, arms and hands $[1,3,4]$, and affect mostly fair-skinned individuals [5].

$\mathrm{AK}$ are in situ dysplastic lesions that can progress to invasive squamous cell carcinoma (SCC) $[4,5]$. Histopathological studies have revealed that clinically visible $\mathrm{AK}$ lesions are often accompanied by subclinical or invisible lesions which, if untreated, might result in field cancerisation [6]. Thus, early diagnosis and therapy initiation, even at the stage of grade I lesions, are of great importance for patient prognosis $[3,7,8]$.

Treatment of AK ranges from the removal of individual lesions (e.g. cryosurgery, excision) to the treatment of the wider field (e.g. topical therapies, photodynamic therapy) [1,9-11] and depends on patient preference and their clinical circumstances. The number of visible AKs is a poor indicator of the real number of lesions present in the field of cancerisation, underlying the importance of treating the whole field of cancerisation using field-directed treatments for multiple AKs [12].

The aim of AK therapy is to achieve a good response rate (i.e. reduction of the extent of field cancerisation) and/or clearance (complete and partial) of clinical and subclinical lesions, to prevent progression to invasive SCC, to 
improve skin appearance, to minimise pain and other symptoms, and to reduce lesion recurrence $[1,3,6,13]$.

Since its approval 50 years ago, 5-fluorouracil (5-FU) has been the mainstay treatment for AK. Owing to its efficacy, ease of use and cost-effectiveness, 5-FU is one of the most commonly used topical medications for both lesion-directed and field-directed treatment of $\mathrm{AK}$ $[1,9,14-18]$. However, 5-FU topical treatment is also associated with adverse local skin reactions, which are probably due to a local inflammatory response related to its mechanism of action.

5 -FU 4\% cream $\left(\right.$ Tolak $^{\circledR}$ ) is indicated for the topical treatment of non-hyperkeratotic, nonhypertrophic actinic keratosis (Olsen grade I and II) of the face, ears, and/or scalp in adults $[19,20]$, and was approved on the basis of data from two well-controlled phase III primary efficacy studies (HD-FUP3B-048 and HD-FUP3B049). The results of the study HD-FUP3B-048 have been published previously alongside those of a phase II study (HD-FUDR-045) [21]. In these two studies, 5-FU 4\% cream once daily demonstrated similar rates of complete $(54.4 \%$ vs $57.9 \%$ and partial clearance of AK lesions $(80.5 \%$ vs $80.2 \%)$ to the original formulation of 5-FU 5\% cream applied twice daily [21].

The occurrence of severe local adverse skin reactions during treatment can affect patient adherence to therapy and therefore compromise efficacy. This pooled analysis of data from the two phase III trials (HD-FUP3B-048 and HDFUP3B-049) had two aims. The first was to compare severe local skin reactions between 5 -FU 4\% cream applied once daily and 5-FU 5\% cream applied twice daily. The second was to explore the relationship between the severity of local skin reactions during treatment with oncedaily 5 -FU $4 \%$ cream and the number of $\mathrm{AK}$ lesions at baseline.

\section{METHODS}

\section{Study Design and Patients}

This was a post hoc, exploratory analysis of pooled data of safety populations from two multicentre, randomised phase III studies: HD-
FUP3B-048 [21] and HD-FUP3B-049 (unpublished). The design of each study was comparable, with similar active treatment regimens and study endpoints. Study HD-FUP3B-048 had two active treatments (5-FU $4 \%$ and 5\% cream) and vehicle control groups, whereas study HDFUP3B-049 had one active treatment (5-FU 4\%) and a vehicle control group.

Participants from both studies were eligible for inclusion if they had at least five clinically recognisable $\mathrm{AK}$ on either their face, ears and/or scalp, were more than 18 years old, and were not pregnant nor intended to be during the duration of the treatment and agreed to use contraceptives. Participants were excluded if they had skin lesions suspected to be SCC, had been treated with any systemic cancer treatment or any other AK treatments including steroids or retinoids in the past 2 months prior to the study, or had or were suspected to develop sensitivity to any of the ingredients in the study medication.

Patients applied 5-FU cream to the entire affected field (i.e. face, ears and/or scalp), either once daily ( $4 \%$ cream) or twice daily ( $5 \%$ cream) for 4 weeks. The creams ( $4 \%$ and $5 \%$ ) were applied to the entire involved field at the same time each day.

The number and severity of skin lesions were evaluated at baseline, week 2 and week 4 . For each patient, the same investigator, who was blinded to treatment allocation, evaluated local skin reactions by visual assessment of erythema, scaling/dryness, oedema, crusting and erosions and by patient questioning about the presence, severity and impact of symptoms (stinging/ burning, pruritus) in the preceding $24 \mathrm{~h}$. The reactions were graded at each visit (without reference to baseline or previous assessments) as an average across all treated areas using a fourpoint numerical scale, where 0 was used to denote none (no evidence of reaction), 1 mild (faintly detectable reaction), 2 moderate (clearly distinguishable reaction) and 3 severe (marked/ extensive/bothersome reaction).

\section{Pooled Analysis}

Patients from the active treatment arms of both studies were eligible for inclusion in this pooled 
analysis. Study HD-FUP3B-048 enrolled a total of 841 patients from 26 sites in the USA [21]; data from 690 enrolled patients were included in the pooled analysis, of whom 348 were in the 5-FU 4\% once daily treatment group and 342 were in the 5 -FU $5 \%$ twice daily treatment group. Of the 100 patients included in study HD-FUP3B-049 from six sites in the USA, data from 49 enrolled patients receiving 5-FU 4\% cream once daily were included in the pooled analysis. The remaining patients enrolled in the two studies either received placebo or had no local skin reaction data available after study inclusion.

\section{Outcome Measures}

We compared the severity of local skin reactions (i.e. erythema, scaling/dryness, oedema, crusting, erosions, stinging/burning or pruritus) with 5 -FU $4 \%$ cream once daily and 5\% cream twice daily at week 4 of treatment using the data from study HD-FUP3B-048. Then, any associations between the number of AK lesions at baseline (categorised in groups of five) and the severity of local skin reactions at week 4 of treatment were assessed for 5-FU 4\% cream once daily using pooled data from study HD-FUP3B-049 and study HD-FUP3B-048.

\section{Statistical Analyses}

Since these were exploratory post hoc analyses, there was no formal statistical protocol. Baseline demographics and patient characteristics are presented descriptively as percentages, means, medians and standard deviations, and were compared using the Student $t$ test, Fisher's exact test, chi-squared test, Cochran-Mantel-Haenszel (CMH) test and Wilcoxon test, as appropriate. The severity of local skin reactions with the two 5-FU regimens was compared using a chi-squared test and the odds ratio (OR) and 95\% confidence intervals (CI) calculated using logistic regression (unadjusted and after adjustment for age). A CMH analysis was also undertaken, stratifying for the number of treated areas $(1,2$ or 3$)$. Any associations between the number of baseline lesions and the severity of local skin reactions were examined at week 4 using Fisher's exact test and two-sided $P$ values were calculated. Because differences were noted in the baseline characteristics of patients using 5 -FU $4 \%$ once daily versus 5 -FU $5 \%$ twice daily, we conducted a post hoc logistic regression analysis on the difference in skin reactions between the groups, adjusting for baseline age, Fitzpatrick skin type, number of lesions and disease severity.

\section{Ethical Considerations}

This pooled analysis was based on previously conducted studies and does not contain any direct investigation with human participants or animals performed by any of the authors. Studies HD-FUP3B-048 and HD-FUP3B-049 received ethical approval from the institutional review boards of all relevant study sites and were conducted in compliance with US Food and Drug Administration regulations, the ethical principles of the Declaration of Helsinki, and the current International Conference on Harmonisation Good Clinical Practice guidelines. Patients provided written informed consent to participate in the studies.

\section{RESULTS}

\section{Patient Characteristics}

Baseline demographics and clinical characteristics of the study participants were generally similar between the various treatment arms (5FU $4 \%$ and 5\%) in study HD-FUP3B-048 (Table 1). Compared with patients receiving 5 -FU $4 \%$ once daily in study HD-FUP3B-048, those receiving 5 -FU $4 \%$ once daily in study HD-FUP3B-049 had significantly more lesions $(P=0.0031)$ and more severe AK $(P=0.0045)$ and included significantly more patients with darker Fitzpatrick skin types $(P=0.0083)$ (Table 1). In the overall patient population, the majority of patients were aged at least 60 years old (range 36.7-94.1 years) and were male (81\%). Most patients had skin type I-III (94.6\%) and the number of $\mathrm{AK}$ ranged from 5 to 83 
Table 1 Baseline demographics and clinical characteristics of the enrolled study populations

\begin{tabular}{|c|c|c|c|}
\hline & \multicolumn{2}{|c|}{ Study HD-FUP3B-048 } & \multirow{2}{*}{$\begin{array}{l}\text { Study HD-FUP3B-049 } \\
5 \text {-FU 4\% cream } \\
(N=50)\end{array}$} \\
\hline & $\begin{array}{l}\text { 5-FU 4\% cream } \\
(N=353)\end{array}$ & $\begin{array}{l}\text { 5-FU 5\% cream } \\
(N=349)\end{array}$ & \\
\hline \multicolumn{4}{|l|}{ Age, years } \\
\hline Mean (SD) & $67.7(9.8)$ & $67.4(10.0)$ & $67.9(11.7)$ \\
\hline Range & $36.7-88.9$ & $37.6-94.1$ & $44.7-85.1$ \\
\hline Between-group $P$ value & $0.6586^{\mathrm{a} 1}$ & & $0.9439^{\mathrm{b} 1}$ \\
\hline \multicolumn{4}{|l|}{ Sex, $n(\%)$} \\
\hline Male & $287(81)$ & $282(81)$ & $39(78)$ \\
\hline Female & $66(19)$ & $67(19)$ & $11(22)$ \\
\hline Between-group $P$ value & $0.8656^{\mathrm{a} 2}$ & & $0.5782^{\mathrm{b} 2}$ \\
\hline \multicolumn{4}{|l|}{ Race, $n(\%)$} \\
\hline White & $348(99)$ & $347(99)$ & $50(100)$ \\
\hline American Indian/Alaska Native & $1(<1)$ & 0 & 0 \\
\hline Other & $4(1)$ & $2(1)$ & 0 \\
\hline Between-group $P$ value & $0.6862^{\mathrm{a} 3}$ & & $1.000^{\mathrm{b} 3}$ \\
\hline \multicolumn{4}{|l|}{ Skin type, $n(\%)$} \\
\hline I & $84(24)$ & $91(26)$ & $7(14)$ \\
\hline II & $178(50)$ & $155(44)$ & $17(34)$ \\
\hline III & $75(21)$ & $80(23)$ & $25(50)$ \\
\hline IV & $13(4)$ & $21(6)$ & $1(2)$ \\
\hline $\mathrm{V}$ & $3(1)$ & $2(1)$ & 0 \\
\hline VI & 0 & 0 & 0 \\
\hline Between-group $P$ value & $0.6136^{\mathrm{a} 4}$ & & $0.0084^{\mathrm{b} 4}$ \\
\hline \multicolumn{4}{|l|}{ Number of lesions } \\
\hline Median & 11 & 12 & 14 \\
\hline Range & $5-76$ & $5-76$ & $5-83$ \\
\hline Between-group $P$ value & $0.1846^{\mathrm{a} 5}$ & & $0.0031^{\mathrm{b} 5}$ \\
\hline
\end{tabular}


Table 1 continued

\begin{tabular}{|c|c|c|c|}
\hline & \multicolumn{2}{|c|}{ Study HD-FUP3B-048 } & \multirow{2}{*}{$\begin{array}{l}\text { Study HD-FUP3B-049 } \\
\text { 5-FU 4\% cream } \\
(N=50)\end{array}$} \\
\hline & $\begin{array}{l}\text { 5-FU 4\% cream } \\
(N=353)\end{array}$ & $\begin{array}{l}\text { 5-FU 5\% cream } \\
(N=349)\end{array}$ & \\
\hline \multicolumn{4}{|l|}{ Disease severity $^{\mathrm{c}}, n(\%)$} \\
\hline Mild & $171(48)$ & $154(44)$ & $13(26)$ \\
\hline Moderate & $138(39)$ & $162(46)$ & $27(54)$ \\
\hline Severe & $44(12)$ & $33(9)$ & $10(20)$ \\
\hline Between-group $P$ value & $0.7960^{\mathrm{a} 4}$ & & $0.0045^{\mathrm{b} 4}$ \\
\hline \multicolumn{4}{|c|}{ 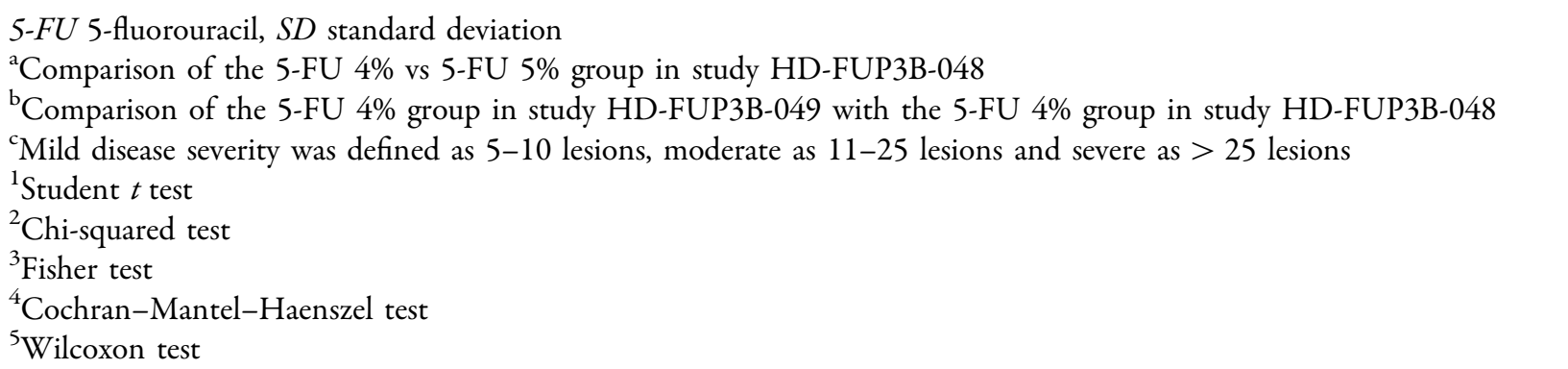 } \\
\hline
\end{tabular}

lesions. Disease severity at baseline was mild to moderate in the majority of patients $(88.4 \%$; Table 1).

\section{Local Skin Reaction Severity: 5-FU 4\% vs 5-FU 5\% Cream}

Severe skin reactions were more common with 5-FU 5\% cream applied twice daily than with 5-FU 4\% cream applied once daily at week 4 when skin reactions were maximal (Table 2). Significantly more patients treated with 5-FU 5\% versus $4 \%$ cream reported severe erythema (47\% vs 37\%), severe scaling/dryness or crusting (both $25 \%$ vs $18 \%$ ), severe stinging/burning (27\% vs $18 \%)$ and severe pruritus (22\% vs $13 \%$; all $P<0.05$ ). The rates of severe oedema ( $8 \%$ vs $5 \%$ of patients; $P=0.2081$ ) and severe skin erosions (12\% vs $8 \% ; P=0.1495$ ) were similar between treatment groups (Table 2). Similar significant differences were seen in the logistic regression analyses, including the unadjusted analysis, the age-adjusted analysis, and after adjustment for age, skin type, lesion number and disease severity. In addition, the results of the $\mathrm{CMH}$ analysis stratified by the number of treated areas were also consistent, with significant between-group differences in erythema $(P=0.0080)$, scaling/dryness $\quad(P=0.0131)$, crusting $\quad(P=0.0179)$, stinging/burning $(P=0.0085)$ and pruritus $(P=0.0032)$, but no significant difference in oedema $(P=0.1773)$ or erosions $(P=0.1356)$.

\section{Severity of Local Skin Reactions by Number of Baseline Lesions}

Figure 1, Table 3 and Supplementary Table 1 show a potential relationship between the number of $\mathrm{AK}$ lesions at baseline and the severity of local skin reactions after 4 weeks of treatment with 5 -FU $4 \%$ cream once daily. In general, local skin reactions appeared to be more severe in patients with more than 10 lesions at baseline than in patients with fewer pre-treatment lesions (Fig. 1). For example, the number of patients with erythema was higher in patients with more than 10 lesions at baseline, with $46 \%$ of patients experiencing severe erythema in comparison with $28 \%$ of patients who had 5-10 lesions at baseline (Table 3). In 
Table 2 Summary of local skin reactions at week 4 of treatment with either 5 -fluorouracil $4 \%$ or $5 \%$ cream (safety population study HD-FUP3B-048)

\begin{tabular}{|c|c|c|c|c|c|}
\hline Reaction by severity, $n\left(\%^{\mathrm{a}}\right)$ & $\begin{array}{l}5-\mathrm{FU} 4 \% \\
\text { cream OD } \\
n=348\end{array}$ & $\begin{array}{l}5 \text {-FU } 5 \% \\
\text { cream BID } \\
n=342\end{array}$ & $\begin{array}{l}\text { Unadjusted } \\
\text { OR }(95 \% \mathrm{CI})\end{array}$ & $\begin{array}{l}\text { Age-adjusted } \\
\text { OR (95\% CI) }\end{array}$ & $\begin{array}{l}\text { Multivariate-adjusted } \\
\text { OR }(95 \% \mathrm{CI})^{\mathbf{b}}\end{array}$ \\
\hline \multicolumn{6}{|l|}{ Erythema } \\
\hline \multirow[t]{2}{*}{ Severe } & 120 & 140 & 1.517 & 1.506 & 1.550 \\
\hline & $(37)$ & $(47)$ & $(1.102 ; 2.087)$ & $(1.094 ; 2.074)$ & $(1.114 ; 2.154)$ \\
\hline \multirow[t]{2}{*}{ Non-severe (none/mild/moderate) } & 208 & 160 & & & \\
\hline & $(63)$ & $(53)$ & & & \\
\hline Not reported & 20 & 42 & & & \\
\hline$P$ value & $0.0104^{\mathrm{c}}$ & & $0.0106^{\mathrm{d}}$ & $0.0121^{\mathrm{d}}$ & $0.0092^{\mathrm{d}}$ \\
\hline \multicolumn{6}{|l|}{ Scaling/dryness } \\
\hline \multirow[t]{2}{*}{ Severe } & 57 & 75 & 1.592 & 1.581 & 1.691 \\
\hline & $(17)$ & $(25)$ & $(1.081 ; 2.345)$ & $(1.073 ; 2.330)$ & $(1.131 ; 2.527)$ \\
\hline \multirow[t]{2}{*}{ Non-severe (none/mild/moderate) } & 271 & 224 & & & \\
\hline & $(83)$ & $(75)$ & & & \\
\hline Not reported & 20 & 43 & & & \\
\hline$P$ value & $0.0181^{\mathrm{c}}$ & & $0.0186^{\mathrm{d}}$ & $0.0205^{\mathrm{d}}$ & $0.0104^{\mathrm{d}}$ \\
\hline \multicolumn{6}{|l|}{ Oedema } \\
\hline \multirow[t]{2}{*}{ Severe } & 18 & 24 & 1.498 & 1.487 & 1.503 \\
\hline & $(5)$ & $(8)$ & $(0.796 ; 2.818)$ & $(0.790 ; 2.801)$ & $(0.783 ; 2.887)$ \\
\hline Non-severe (none/mild/moderate) & $310(95)$ & $276(92)$ & & & \\
\hline Not reported & 20 & 42 & & & \\
\hline$P$ value & $0.2081^{c}$ & & $0.2106^{\mathrm{d}}$ & $0.2188^{\mathrm{d}}$ & $0.2210^{\mathrm{d}}$ \\
\hline \multicolumn{6}{|l|}{ Crusting } \\
\hline \multirow[t]{2}{*}{ Severe } & 56 & 74 & 1.590 & 1.615 & 1.703 \\
\hline & $(17)$ & $(25)$ & $(1.077 ; 2.347)$ & $(1.092 ; 2.387)$ & $(1.140 ; 2.544)$ \\
\hline Non-severe (none/mild/moderate) & $272(83)$ & $226(75)$ & & & \\
\hline Not reported & 20 & 42 & & & \\
\hline$P$ value & $0.0190^{\mathrm{c}}$ & & $0.0195^{\mathrm{d}}$ & $0.0163^{\mathrm{d}}$ & $0.0094^{\mathrm{d}}$ \\
\hline \multicolumn{6}{|l|}{ Erosions } \\
\hline \multirow[t]{2}{*}{ Severe } & 27 & 35 & 1.472 & 1.500 & 1.571 \\
\hline & $(8)$ & $(12)$ & $(0.868 ; 2.498)$ & $(0.883 ; 2.549)$ & $(0.914 ; 2.701)$ \\
\hline \multirow[t]{2}{*}{ Non-severe (none/mild/moderate) } & 301 & 265 & & & \\
\hline & $(92)$ & $(88)$ & & & \\
\hline Not reported & 20 & 42 & & & \\
\hline$P$ value & $0.1495^{\mathrm{c}}$ & & $0.1513^{\mathrm{d}}$ & $0.1340^{\mathrm{d}}$ & $0.1022^{\mathrm{d}}$ \\
\hline
\end{tabular}


Table 2 continued

\begin{tabular}{|c|c|c|c|c|c|}
\hline Reaction by severity, $n\left(\%^{a}\right)$ & $\begin{array}{l}5 \text {-FU } 4 \% \\
\text { cream OD } \\
n=348\end{array}$ & $\begin{array}{l}5 \text {-FU } 5 \% \\
\text { cream BID } \\
n=342\end{array}$ & $\begin{array}{l}\text { Unadjusted } \\
\text { OR }(95 \% \mathrm{CI})\end{array}$ & $\begin{array}{l}\text { Age-adjusted } \\
\text { OR ( } 95 \% \mathrm{CI})\end{array}$ & $\begin{array}{l}\text { Multivariate-adjusted } \\
\text { OR }(95 \% \mathrm{CI})^{\mathrm{b}}\end{array}$ \\
\hline \multicolumn{6}{|l|}{ Stinging/burning } \\
\hline \multirow[t]{2}{*}{ Severe } & 60 & 81 & 1.652 & 1.659 & 1.652 \\
\hline & $(18)$ & $(27)$ & $(1.131 ; 2.412)$ & $(1.135 ; 2.423)$ & $(1.121 ; 2.433)$ \\
\hline \multirow[t]{2}{*}{ Non-severe (none/mild/moderate) } & 268 & 219 & & & \\
\hline & $(82)$ & $(73)$ & & & \\
\hline Not reported & 20 & 42 & & & \\
\hline$P$ value & $0.0090^{\mathrm{c}}$ & & $0.0094^{\mathrm{d}}$ & $0.0089^{\mathrm{d}}$ & $0.0111^{\mathrm{d}}$ \\
\hline \multicolumn{6}{|l|}{ Pruritus } \\
\hline \multirow[t]{2}{*}{ Severe } & 43 & 66 & 1.869 & 1.876 & 1.875 \\
\hline & (13) & $(22)$ & $(1.227 ; 2.849)$ & $(1.231 ; 2.860)$ & $(1.215 ; 2.894)$ \\
\hline \multirow[t]{2}{*}{ Non-severe (none/mild/moderate) } & 285 & 234 & & & \\
\hline & $(87)$ & $(78)$ & & & \\
\hline Not reported & 20 & 42 & & & \\
\hline$P$ value & $0.0033^{c}$ & & $0.0036^{\mathrm{d}}$ & $0.0034^{\mathrm{d}}$ & $0.0045^{\mathrm{d}}$ \\
\hline \multicolumn{6}{|c|}{$\begin{array}{l}\text { Data from } 348 \text { patients who received 5-FU } 4 \% \text { cream and } 342 \text { patients who received 5-FU 5\% cream in study HD-FUP3B-0 } 48 \text { were considered } \\
\text { for the safety analysis }\end{array}$} \\
\hline \multicolumn{6}{|c|}{${ }^{\text {a}}$ Percentage values calculated using the total number of patients with available data as the denominator (excludes patients with missing values) } \\
\hline \multirow{2}{*}{\multicolumn{6}{|c|}{$\begin{array}{l}\text { bAdjusted for age, Fitzpatrick skin type (types IV and V were pooled together because of the low number of patients with type V), number of } \\
\text { lesions, and disease severity }\end{array}$}} \\
\hline & & & & & \\
\hline \multicolumn{6}{|l|}{${ }^{\mathrm{c} C h i-s q u a r e d ~ t e s t ~}$} \\
\hline \multicolumn{6}{|l|}{${ }^{\mathrm{d}}$ Logistic regression analysis } \\
\hline
\end{tabular}

addition, a greater proportion of patients with more than 10 lesions at baseline showed severe oedema, nevertheless, the proportion of patients with severe skin oedema was relatively low (less than 15\%) irrespective of the number of lesions at baseline (Fig. 1b and Supplementary Table 1).

For some skin reactions, the distinction was notable at the 15-lesion cut-off; for example, patients with more than 15 lesions at baseline had more than twice the rate of severe scaling in comparison with patients who had 11-15 skin lesions at baseline (Fig. 1c and d, Supplementary Table 1). Pruritus and stinging were typically mild or moderate in severity regardless of the number of lesions, but when the number of lesions was greater than 15 at baseline, there was a higher incidence of moderate or severe pruritus or stinging than in patients with fewer lesions (Fig. 1f and g, Supplementary Table 1).

To confirm these graphical trends, we compared the proportion of patients presenting with a severe reaction using the 10-lesion cutoff. All local skin reactions were significantly more severe in the subgroup of patients with more than 10 baseline lesions than in patients with 5-10 lesions $(P<0.05$; Table 3$)$.

\section{DISCUSSION}

Results from this exploratory analysis confirm that severe local skin reactions were less 


\section{A}

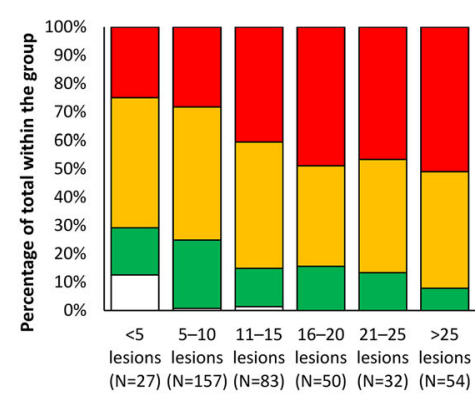

D

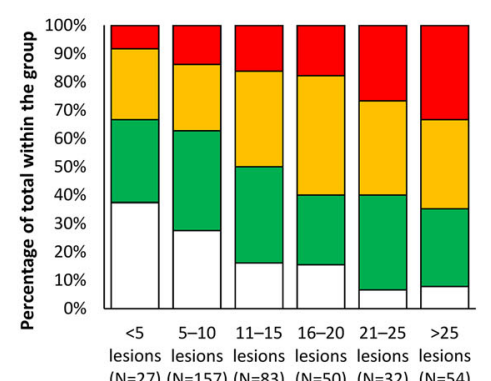

G

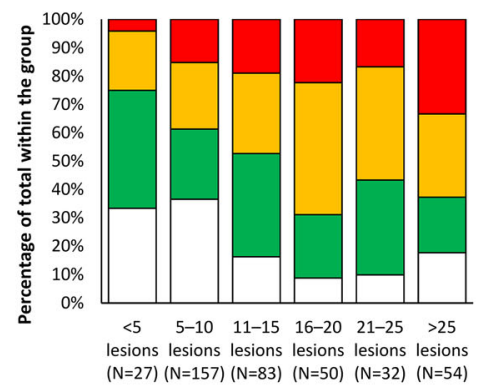

B

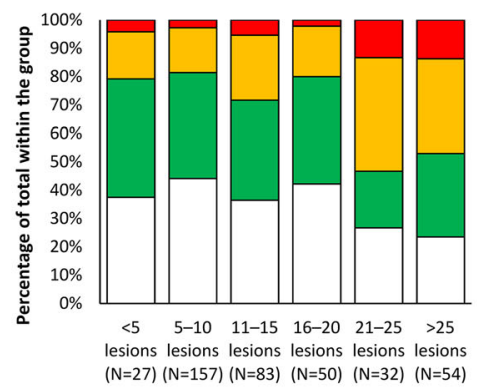

E

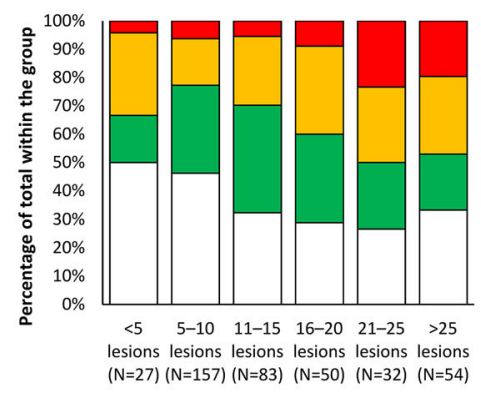

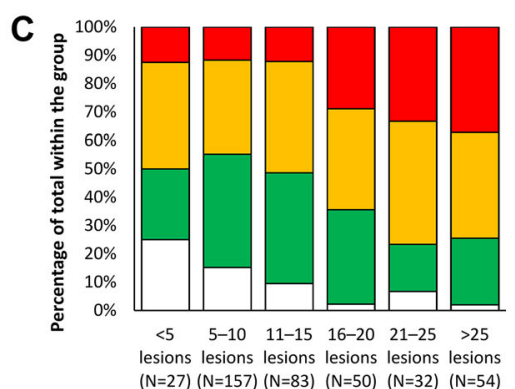

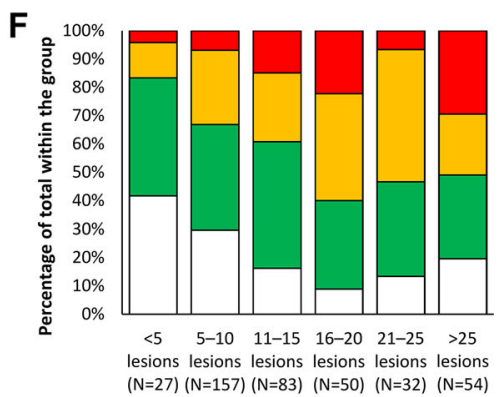

Fig. 1 Relationship between the number of lesions at baseline and severity of a erythema, $\mathbf{b}$ oedema, c scaling, $\mathbf{d}$ crusting, $\mathbf{e}$ erosion, $\mathbf{f}$ pruritus and $\mathbf{g}$ stinging during treatment of actinic keratosis with 5 -fluorouracil $4 \%$ cream once daily at week 4 . Local skin reactions were graded as a

frequent with 5-FU 4\% cream applied once daily compared with the $5 \%$ formulation applied twice daily. More interestingly, the occurrence of severe local skin reactions was related to the number of lesions at baseline. Local skin reactions (i.e. erythema, scaling/dryness, oedema, crusting, erosions, stinging/burning and pruritus) were maximal after 4 weeks of treatment with 5 -FU $4 \%$ cream and appeared to be more severe in patients with more than 10 lesions at baseline compared with those with 5-10 lesions. This suggests that a threshold of 10 lesions pre-treatment could be considered a good predictor of more severe local skin reactions.

visual average across all treated areas using a 4-point numerical scale: 0 (none; no evidence of reaction), 1 (mild; faintly detectable reaction), 2 (moderate; clearly distinguishable reaction) or 3 (severe; marked/extensive/bothersome reaction)

The established treatment for AK is generally 5 -FU 5\% cream applied once or twice daily for 4 weeks [10, 16, 18]. However, while 5 -FU has proven efficacy, this treatment is often associated with adverse events that some patients may find difficult to tolerate, discontinuing their treatment early and thus reducing the duration of treatment and compromising its efficacy [9]. As shown in this analysis, the frequency of severe local skin reactions is lower when using the once-daily 5 -FU $4 \%$ cream than the 5-FU 5\% cream twice daily. In addition, given the effect of tolerability on treatment adherence, predicting which patients may have more severe skin reactions during treatment 
Table 3 Comparison of the severity of local skin reactions at week 4 of actinic keratosis with 5 -fluorouracil $4 \%$ cream in patients with $0-10$ vs $>10$ lesions at baseline (pooled 5-fluorouracil 4\% populations from study HD-FUP3B-048 and study HD-FUP3B-049)

\begin{tabular}{|c|c|c|c|}
\hline \multirow[t]{2}{*}{ Reaction by severity, $n$ (\%) } & \multicolumn{2}{|c|}{ Number of actinic keratosis lesions at baseline } & \multirow{2}{*}{$\begin{array}{l}P \text { value } \\
\text { (2-sided) }\end{array}$} \\
\hline & $\begin{array}{l}0-10 \\
(N=169)\end{array}$ & $\begin{array}{l}>10 \\
(N=200)\end{array}$ & \\
\hline Severity of erythema & & & 0.0004 \\
\hline None/mild/moderate & $122(72)$ & $108(54)$ & \\
\hline Severe & $47(28)$ & $92(46)$ & \\
\hline Severity of oedema & & & 0.0430 \\
\hline None/mild/moderate & $164(97)$ & $184(92)$ & \\
\hline Severe & $5(3)$ & $16(8)$ & \\
\hline Severity of scaling & & & 0.0009 \\
\hline None/mild/moderate & $149(88)$ & $149(74)$ & \\
\hline Severe & $20(12)$ & $51(25)$ & \\
\hline Severity of crusting & & & 0.0212 \\
\hline None/mild/moderate & $147(86)$ & $155(77)$ & \\
\hline Severe & $22(13)$ & $45(22)$ & \\
\hline Severity of erosions & & & 0.0334 \\
\hline None/mild/moderate & $159(94)$ & $175(87)$ & \\
\hline Severe & $10(6)$ & $25(12)$ & \\
\hline Severity of pruritus & & & 0.0004 \\
\hline None/mild/moderate & $158(93)$ & $162(81)$ & \\
\hline Severe & $11(7)$ & $38(19)$ & \\
\hline Severity of stinging & & & 0.0230 \\
\hline None/mild/moderate & $146(86)$ & $154(77)$ & \\
\hline Severe & $23(14)$ & $46(23)$ & \\
\hline
\end{tabular}

The severity of local reactions was measured at week 2 and week 4; week 4 data are shown in this table. Local skin reactions were graded as a visual average across all treated areas using a 4-point numerical scale: 0 (none; no evidence of reaction), 1 (mild; faintly detectable reaction), 2 (moderate; clearly distinguishable reaction) or 3 (severe; marked/extensive/bothersome reaction)

Data were missing for 34 patients

with 5-FU cream could be important in ensuring that these patients are adequately informed and managed. This post hoc analysis helped to define a cut-off value of 10 lesions pre-treatment that could help healthcare practitioners to inform patients and to prevent the potentially more severe local adverse skin reactions. This could help improve patient treatment adherence.

In the current study, statistically significant associations between the number of baseline lesions and the severity of local skin reactions 
were shown after 4 weeks of treatment. Hence, future studies could include a formal evaluation of the relationship between the intensity and frequency of local reactions at week 2 with severe local reactions at week 4 (i.e. the pattern of development of local skin reactions over time). Additionally, it would also be useful to know whether the intensity of local reactions (moderate to severe) is predictive of better clearance of lesions, by analysing the severity of reactions at weeks $2-4$ versus the complete clearance rate 4 weeks after completing treatment.

A limitation of the current study is its post hoc exploratory nature and thus confirmation of these findings in a prospective study would be preferable. Additional limitations included the lack of assessment of treatment adherence, and whether any patients who experienced moderate or severe local skin reactions discontinued treatment or skipped treatment applications; examination of these issues would be useful in future studies. In addition, the grading scale for the assessment of local skin reactions was not validated and inter-reliability was not evaluated prior to its use in the study.

\section{CONCLUSIONS}

The results from this analysis provide further evidence to support the treatment of patients with AK with 5-FU 4\% cream. Treatment with 5 -FU $4 \%$ cream once daily was associated with less severe local skin reactions compared with twice daily application of 5-FU 5\%. The number of lesions at baseline seems to have predictive value regarding the severity of local skin reactions that appear during treatment. Using a cutoff value of 10 lesions pre-treatment, healthcare practitioners can forewarn patients accordingly of potentially more severe local adverse skin reactions. Given that a higher number of lesions at baseline is likely to be predictive of a greater severity of local skin reactions during treatment, healthcare practitioners should plan appropriately for the management of these patients, with the aim of helping patients persist with their treatment despite such reactions. All patients using 5-FU topical cream should be counselled to use moisturisers and topical steroids to manage severe reactions. However, in patients with more than 10 lesions, proactive patient management may also include continuous monitoring, patient education to manage their expectations of treatment, and other preventive treatments for, or prompt management of, local skin reactions.

\section{ACKNOWLEDGEMENTS}

Funding. Sponsorship for these analyses, the Rapid Service Fee and medical writing services were funded by Pierre Fabre Dermatologie.

Medical Writing Assistance. We would like to thank Andrea Bothwell who wrote the outline of this manuscript on behalf of Springer Healthcare Communications and Alma OrtsSebastian, of Springer Healthcare Communications, who wrote the first draft. This medical writing assistance was funded by Pierre Fabre Dermatologie.

Authorship. All named authors meet the International Committee of Medical Journal Editors (ICMJE) criteria for authorship for this article, take responsibility for the integrity of the work as a whole, and have given their approval for this version to be published.

Author Contributions. All authors played equal roles in the concept and planning of the work described; acquisition, analysis and interpretation of the data; critical revision of the manuscript; and approved the final submitted version of the manuscript.

Disclosures. Eggert Stockfleth has received fees from Pierre Fabre for acting as a medical and scientific advisor, speaker and investigator. Nathalie Bégeault and Alain Delarue are employees of Pierre Fabre.

Compliance with Ethics Guidelines. This pooled analysis was based on previously conducted studies and does not contain any direct investigation with human participants or 
animals performed by any of the authors. Studies HD-FUP3B-048 and HD-FUP3B-049 received ethical approval from the institutional review boards of all relevant study sites and were conducted in compliance with US Food and Drug Administration regulations, the ethical principles of the Declaration of Helsinki, and the current International Conference on Harmonisation Good Clinical Practice guidelines. Patients provided written informed consent to participate in the studies.

Data Availability. The datasets analysed during the current study are available from the corresponding authors on reasonable request.

Open Access. This article is licensed under a Creative Commons Attribution-NonCommercial 4.0 International License, which permits any non-commercial use, sharing, adaptation, distribution and reproduction in any medium or format, as long as you give appropriate credit to the original author(s) and the source, provide a link to the Creative Commons licence, and indicate if changes were made. The images or other third party material in this article are included in the article's Creative Commons licence, unless indicated otherwise in a credit line to the material. If material is not included in the article's Creative Commons licence and your intended use is not permitted by statutory regulation or exceeds the permitted use, you will need to obtain permission directly from the copyright holder. To view a copy of this licence, visit http://creativecommons.org/licenses/by$\mathrm{nc} / 4.0 /$.

\section{REFERENCES}

1. de Berker D, McGregor JM, Mohd Mustapa MF, Exton LS, Hughes BR. British Association of Dermatologists' guidelines for the care of patients with actinic keratosis 2017. Br J Dermatol. 2017;176(1): 20-43.

2. Stockfleth E, Kerl H, Zwingers T, Willers C. Lowdose 5-fluorouracil in combination with salicylic acid as a new lesion-directed option to treat topically actinic keratoses: histological and clinical study results. Br J Dermatol. 2011;165(5):1101-8.
3. Szeimies R-M, Atanasov P, Bissonnette R. Use of lesion response rate in actinic keratosis trials. Dermatol Ther (Heidelb). 2016;6(4):461-4.

4. Criscione VD, Weinstock MA, Naylor MF, et al. Actinic keratoses: natural history and risk of malignant transformation in the Veterans Affairs Topical Tretinoin Chemoprevention Trial. Cancer. 2009;115(11):2523-30.

5. Traianou A, Ulrich M, Apalla Z, et al. Risk factors for actinic keratosis in eight European centres: a casecontrol study. Br J Dermatol. 2012;167(Suppl 2): 36-42.

6. Dirschka T, Gupta G, Micali G, et al. Real-world approach to actinic keratosis management: practical treatment algorithm for office-based dermatology. J Dermatolog Treat. 2017;28(5):431-42.

7. Huyke C, Reuter J, Rödig M, et al. Treatment of actinic keratoses with a novel betulin-based oleogel. A prospective, randomized, comparative pilot study. J Dtsch Dermatol Ges. 2009;7(2):128-33.

8. Stockfleth E, von Kiedrowski R, Dominicus R, et al. Efficacy and safety of 5-fluorouracil $0.5 \%$ /salicylic acid 10\% in the field-directed treatment of actinic keratosis: a phase III, randomized, double-blind, vehicle-controlled trial. Dermatol Ther (Heidelb). 2017;7(1):81-96.

9. Poulin Y, Lynde CW, Barber K, et al. Non-melanoma skin cancer in Canada Chapter 3: management of actinic keratoses. J Cutan Med Surg. 2015;19(3):227-38.

10. Werner RN, Jacobs A, Rosumeck S, Erdmann R, Sporbeck B, Nast A. Methods and Results Reportevidence and consensus-based (S3) guidelines for the treatment of actinic keratosis-International League of Dermatological Societies in cooperation with the European Dermatology Forum. J Eur Acad Dermatol Venereol. 2015;29(11):e1-66.

11. Fleming P, Zhou S, Bobotsis R, Lynde C. Comparison of the treatment guidelines for actinic keratosis: a critical appraisal and review. J Cutan Med Surg. 2017;21(5):408-17.

12. Stockfleth E. The importance of treating in the field of actinic keratosis lesions. J Eur Acad Dermatol Venereol. 2017;31(Suppl 2):8-11.

13. Ezzedine K, Painchault C, Brignone M. Use of complete clearance for assessing treatment efficacy for 5-fluorouracil interventions in actinic keratoses: how baseline lesion count can impact this outcome. J Mark Access Health Policy. 2020;8(1): 1829884 . 
14. Piquero-Casals J, Morgado-Carrasco D, Gilaberte Y, et al. Management pearls on the treatment of actinic keratoses and field cancerization. Dermatol Ther (Heidelb). 2020;10(5):903-15.

15. Jansen MHE, Kessels J, Merks I, et al. A trial-based cost-effectiveness analysis of topical 5-fluorouracil vs. imiquimod vs. ingenol mebutate vs. methyl aminolaevulinate conventional photodynamic therapy for the treatment of actinic keratosis in the head and neck area performed in the Netherlands. Br J Dermatol. 2020;183(4):738-44.

16. Jansen MHE, Kessels J, Nelemans PJ, et al. Randomized trial of four treatment approaches for actinic keratosis. N Engl J Med. 2019;380(10): 935-46.

17. Gupta AK, Paquet M, Villanueva E, Brintnell W. Interventions for actinic keratoses. Cochrane Database Syst Rev. 2012;12(12):CD004415.
18. Wu Y, Tang N, Cai L, Li Q. Relative efficacy of 5-fluorouracil compared with other treatments among patients with actinic keratosis: a network meta-analysis. Dermatol Ther. 2019;32(3): e12822.

19. Pierre Fabre Dermatologie. Tolak $40 \mathrm{mg} / \mathrm{g}$ cream: summary of product characteristics. 2020. https:// docetp.mpa.se/LMF/Tolak\%20cream\%20ENG\% 20SmPC_09001bee809dbaa1.pdf. Accessed 8 Dec 2020.

20. Hill Dermaceuticals Inc. TOLAK (fluorouracil) cream, 4\%, for topical use. 2015. https://www. accessdata.fda.gov/drugsatfda_docs/nda/2015/ 022259Orig1s000TOC.cfm. Accessed 8 Dec 2020.

21. Dohil MA. Efficacy, safety, and tolerability of $4 \%$ 5 -fluorouracil cream in a novel patented aqueous cream containing peanut oil once daily compared with 5\% 5-fluorouracil cream twice daily: meeting the challenge in the treatment of actinic keratosis. J Drugs Dermatol. 2016;15(10):1218-24. 